\title{
Face à gripe, paciência e tranquilidade - Versão $n^{\circ} 9$
}

Juan Gérvas*

\section{RESUMO}

A gripe A é muito contagiosa e pouco grave. Menos grave do que a gripe habitual de todos os anos (gripe sazonal).

Face à gripe $\mathrm{A}$ é conveniente manter um comportamento prudente e tranquilo, similar ao que temos com a gripe sazonal. Deve-se consultar o médico apenas em caso de enfermidade importante (tosse com sangue, grande deterioração respiratória).

Os antivirais Tamiflu e o Relenza não previnem a gripe A, têm efeitos secundários importantes. Devem reservar-se para tratar casos graves.

A vacina contra a gripe A é experimental, e por agora não se sabe nada sobre a sua segurança ou sobre a sua eficácia.

As pandemias prévias não produziram grande mortalidade desde que se passou a dispor de antibióticos para tratar as pneumonias que complicam a gripe. Essas pandemias também não tiveram um segundo surto de maior agressividade.

Para além da gripe $A$, os serviços de saúde têm que atender os milhares de doentes agudos e crónicos habituais, pelo que convém não saturar a actividade de médicos, enfermeiras e restante pessoal com pacientes ligeiros com gripe A.

\section{O PROBLEMA}

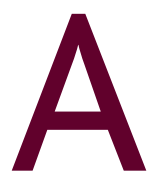

gripe é uma doença viral de que se padece durante o Inverno, sob a forma de epidemia (epidemia sazonal), que afecta grande parte da população. Como diz (e bem) o refrão popular, «a gripe dura sete dias com tratamento, e uma semana sem ele». A gripe é uma enfermidade leve, com febre e sintomas variados tais como dor de cabeça e muscular, náuseas, diarreia e mal-estar geral, que obriga a estar um par de dias em repouso. Não convém baixar a febre a todo o custo (nem sequer nas crianças), e o tratamento é o da dor e do mal-estar.

Pese embora a pouca gravidade da gripe, pode demonstrar-se que a mortalidade aumenta na população em dois picos anuais, um nos dias de Verão com o máximo de calor, e outro nos dias de Inverno com a epidemia de gripe. Por isso se aconselha a vacina contra a gripe, apesar de se discutir a utilidade desta vacinação.

A epidemia de gripe A, que começou no México em 2009, é de menor gravidade que a epidemia habitual. É uma gripe que contagia muito facilmente, e por isso é uma "pandemia», porque pode chegar a afectar uma parte substancial da população. Mas a contagiosidade

*Médico de Canencia de la Sierra, Garganta de los Montes e El Cuadrón (Madrid) Professor Honorário de Saúde Pública na Faculdade de Medicina da Universidad Autónoma de Madrid e Professor Visitante de Atención Primaria en Salud Internacional da Escuela Nacional de Sanidad (Madrid). da gripe A não diz nada sobre a sua gravidade, sendo de facto menos grave do que qualquer das gripes anteriores. Afecta muita gente, mas mata menos do que a gripe sazonal de todos os anos. Os números são variáveis consoante a fonte dos dados, mas por exemplo, no Reino Unido houve centenas de milhares de casos e só umas 30 mortes e nos Estados Unidos da América, com um milhão de casos ocorreram 302 mortos. No Inverno austral (que coincide com o Verão em Espanha - e em Portugal), na Argentina morreram cerca de 350 pessoas, na Austrália perto de de 132, no Chile 128 e na Nova Zelândia faleceram 16 pessoas. Com o Inverno austral quase no fim, no mundo inteiro ocorreram, até agora, 2.501 mortes. Para situar melhor o problema, calcula-se que em Espanha morram durante um Inverno «normal», por gripe sazonal, de 1.500 a 3.000 pessoas.

A mortalidade por gripe A afecta basicamente pessoas de idade inferior a 65 anos, pois os seniores parecem ter algum grau de protecção por terem sido submetidos a epidemias prévias com vírus semelhantes. Nas mortes provocadas pela gripe sazonal cerca de $90 \%$ das pessoas têm mais de 65 anos de idade enquanto que na grupe A só $10 \%$ pertencem a este grupo etário o que é o mesmo que dizer que $90 \%$ da mortalidade por gripe A ocorre em menores de 65 anos. No entanto, em números absolutos, a gripe A mata poucos jovens, por 
exemplo nos EUA morrem anualmente por gripe sazonal cerca de 3.600 pessoas com menos de 65 anos e de gripe A morreram até agora 324 pessoas desse grupo etário. Por gripe sazonal morrem por ano cerca de 36.000 pessoas. A elevada mortalidade nos EUA deve provavelmente à sua falta de cobertura sanitária aos que mais dela necessitam (os pobres e os doentes).

Na Austrália, com o Inverno a terminar, morreram cerca de 132 pessoas por gripe A, das quais só aproximadamente 119 tinham menos de 65 anos. Na Austrália morrem por ano de gripe sazonal cerca de 310 pessoas com menos de 65 anos.

Os factores de risco pouco nos dizem sobre a mortalidade tanto na gripe sazonal como na gripe A. Por exemplo, nos EUA cerca de $67 \%$ das crianças que morreram por gripe sazonal entre 2003-2004 não apresentavam nenhum factor de risco.

Tivemos muitas pandemias, e a mais letal, a «espanhola» de 1918 matou, sobretudo por pneumonias bacterianas, os pobres (mal alimentados, amontoados, com habitações insalubres e mal protegidos do frio). Nas outras duas grandes pandemias, de 1957 e 1968 não houve tal letalidade, entre outras coisas pela existência dos antibióticos para tratar as pneumonias bacterianas.

Ao estudar as pandemias dos últimos séculos (de 1510 à actualidade) demonstra-se que nunca foi contagiada simultaneamente toda a população e que sempre que houve um segundo surto da pandemia a gripe manteve um carácter ligeiro também na segunda volta. A projecção para surtos de gravidade progressiva é uma fantasia, não é uma inferência a partir da realidade. A fantasia está a introduzir o pânico na população quer através da utilização de grandes números («centenas, milhões de pessoas afectadas») quer da descrição de relatos emocionantes quase ao vivo e em directo de cada morte. Estes dois elementos levam o leitor/ /telespectador a ver-se e aos seus familiares próximos afectados pela doença ou mortos. Este é um exercício clássico de «invenção de doença» («disease mongering») de transformação mental de uma gripe A contagiosa e não grave numa gripe A virulenta e letal.

Num dia, o governo Canadiano propôs-se um objectivo duplo frente à gripe aviária: reduzir o número de mortos e manter a estrutura social. Na gripe A o problema não parece ser atingir o primeiro objectivo dado que a sua letalidade é mínima. E o segundo objectivo parece querer ser ignorado quando se propaga uma epidemia de pânico.

\section{O QUE SE PODE FAZER FACE À GRIPE A?}

Quando em 2005 a Organização Mundial de Saúde (OMS) prognosticou que poderiam morrer de gripe aviária até sete milhões de pessoas, desatou-se o pânico no mundo. Depois houve apenas 262 mortes. Assistiu-se, assim, a um gravíssimo erro de prognóstico. Em 2009, com a gripe A, convém não repetir o mesmo erro. Por isso, é central evitar o pânico. É absurdo ter pânico face à epidemia de gripe $\mathrm{A}$, por mais que venha a afectar (levemente) um grande número de pessoas.

Face à gripe A convém fazer o que sempre se faz face à gripe: cuidar-se com prudência e tranquilidade. Boa hidratação, boa alimentação, boa higiene, e recorrer ao médico quando haja sintomas de importância, tipo tosse com expulsão de sangue e grande deterioração da respiração. Convém não tossir para cima de ninguém, não mexer no nariz, tapar a boca ao tossir ou espirrar e lavar as mãos antes de comer, depois de ir à casa de banho e quando estão sujas de mucosidades.

O vírus elimina-se pela mucosidade nasal aproximadamente durante os primeiros cinco dias da enfermidade. O uso de máscaras não parece que ajude a evitar a propagação da epidemia. Convém não fazer muita vida social nesses primeiros dias, como é costume em caso de gripe. No que respeita à gravidez, não há nada a dizer, pois estes cuidados são para se ter sempre, não havendo deste modo nada mais a fazer. A diferença entre estar grávida e não estar é marginal, por exemplo, o risco de internamento por gripe A é de 3 por um milhão nas mulheres grávidas e de uma em cada milhão nas restantes mulheres.

Não há nenhum tratamento preventivo: os medicamentos contra a gripe não previnem a enfermidade (nem o oseltamivir-Tamiflu, nem o zanamivir-Relenza). Uma vez diagnosticada a doença, estes medicamentos são também quase inúteis (tiram meio dia à evolução da enfermidade). Também não existem estudos que avalizem a sua efectividade na gripe A. Para além disso, têm efeitos adversos. Por exemplo, durante a epidemia de gripe A, em crianças tratadas em Londres com oseltamivir - Tamiflu, metade tiveram efeitos adversos, geralmente vómitos, e em 18 \% registaram- 
-se alterações neuropsiquiátricas. Talvez em alguns casos valha a pena o seu uso como tratamento, por exemplo em doentes graves e em pacientes com doenças crónicas importantes, mas não são úteis nem em crianças nem em adultos saudáveis.

A vacina contra a gripe é de pouca utilidade em crianças e adolescentes, com uma efectividade de $33 \%$, e absolutamente inútil nos menores de dois anos. Há dúvidas sobre a sua eficácia em adultos e idosos. Sobre a vacina contra a gripe A não sabemos nada, mas em 1976 produziu-se nos Estados Unidos uma vacina parecida, também com toda a pressa pelo perigo de pandemia, e o resultado foi uma epidemia de efeitos adversos graves (sindroma de Guillain-Barré, uma doença neurológica) que obrigou a parar a vacinação. A pressa não é boa para nada, e ainda menos para parar uma gripe como a A, que tem tão baixa mortalidade. Convém não repetir o erro de 1976. Em todo o caso, é exigível a assinatura de um formulário de «consentimento informado» que deixe claro os benefícios e riscos, e o procedimento a seguir face aos possíveis danos por efeitos adversos. Dada a pressa que há em produzir a vacina, e para evitar as consequências legais relacionadas com os problemas de segurança, em caso de danos serão os Estados, e não a indústria farmacêutica, a responder às reclamações.

\section{MAIS ALGUMA COISA?}

Os testes diagnósticos rápidos da gripe A têm pouca sensibilidade (de 10 a $60 \%$ ). Quer dizer, não vale a pena fazer a determinação para saber se se tem na realidade a gripe A. Tanto faz, pois os conselhos a dar são os mesmos, e o teste não acrescenta a segurança de não se ter a gripe $\mathrm{A}$.

Tanto o vírus da gripe A como o da gripe sazonal podem mutar, inutilizando as vacinas.

A vacinação contra a gripe sazonal não dá protecção contra a gripe A.

Convém não esquecer que uma criança (ou um adulto) pode ter outras enfermidades, além da gripe A. No Reino Unido houve casos de crianças que morreram por meningite por causa de falso diagnóstico de gripe A.

Durante a pandemia de gripe A continuará a haver enfartes do miocárdio, apendicites, insuficiência cardíaca, diabetes, asma, tentativas de suicídio, fracturas da anca, depressão, esquizofrenia e as outras mil enfer- midades que requerem atenção médica. O comportamento sereno, paciente e tranquilo dos pacientes com gripe A é essencial para que os serviços de saúde funcionem bem e para que os médicos e restante pessoal de saúde se possam dedicar aos doentes que deles necessitem, com ou sem gripe A.

\section{NOTA}

O autor não tem outra intenção senão deixar claro o estado do conhecimento acerca da gripe A no momento em que escreve este texto, e para tal reviu a literatura mundial a seu respeito. Este texto é puramente informativo. $\mathrm{O}$ autor lamenta que muitos dos organismos públicos, as sociedades científicas e os meios de comunicação transmitam outra mensagem; terão as suas razões.

Este texto encontra-se traduzido em espanhol, inglês, francês, italiano e português: em: www.equipocesca.es

\section{REFERÊNCIAS SELECCIONADAS}

Bath N,Wright JG, Broder KE e tal. Influenza-associated deaths among children in the United States, 2003-2004. N Engl J Med. 2005; 353:2559-67.

Blumenshine P, Reingold A, Egenter S et al. Pandemic influenza planning in the United States from a health disparities perspective. Emerging Infec Dis. 2008; 14:709-15.

Burch J, Corbett M, Stock $C$ et al. Prescription of anti-influenza drugs for healthy adults: a systematic review and meta-analysis. Lancet Infec Dis. 2009; doi:10.1016/S1473-3099(09)70199-9.

Choweil G,Miller MA,Viboud C. Seasonal influenza in the United States, France and Australai. Transmission and prospects for control. Epidemiol Infect.2008;136:852-64

Ellis C, McEven R. Who should receive Tamiflu for swine flu?. BMJ. 2009; 339:b2698.

Evans D, Cauchemez S, Hayden FG. «Prepandemic» immunization for novel influenza viruses, «swine flu» vaccine, Guillain-Barré syndrome and the detection of rare severe adverse affects. J Infect Dis. 2009; 200:321-8.

Gervas J. Disease mongering by WHO. BMJ.2009 [letter] http://www.bmj. com/eletters/339/aug10_1/b3172

Kitching A, Roche A, Balasegaran S et al. Oseltamivir adherence and side effects among children in three London schools affected by influenza $A$ (H1N1), May 2009. An Internet based cross sectional survey. Eurosurvillance 2009;29:1-4.

Jamieson D, Honein M, Rasmussen S et al. H1N1 2009 influenza virus infection during pregnancy in the USA. Lancet. 2009; July 29.DOI:10.1016/ 50140-6736(09)61304-0

Jefferson TO, Demicheli V, Di Pietrantonj $C$ et al. Inhibidores de neuraminidasa para la prevención y el tratamiento de la influenza en adultos sanos. www.cochrane.es/gripe/revisiones/CD001265.pdf 
Mateo M, Larraux A, Mesonero C. La vigilancia de la gripe. Nuevas soluciones a un viejo problema. Gac Sanit. 2006;20:67-73.

Moreno DM, Taubenberger JK. Understanding influenza backward. JAMA. 2009;302:679-80.

Sheridan C. Flu vaccine makers upgrade technology and pray for it. Nature Biotechnolgy. 2009;27:489-91.

Shun-Shin $M$, Thompson M, Heneghan $C$ et al. Neuraminidase inhibitors for treatment and prophylasis of influenza in children: systematic review and meta-analysis of randomized controlled trials. BMJ. 2009; 339; b3172.

Simonsen L, Taylor RJ, Vibourd C et al. Mortality benefits of influenza vaccine in elderly people: an ongoing controversy. Lancet Infect Dis. 2007; 7: 658-66.

Smith S, Demicheli V, Di Pietrantonj C, Harden AR et al. Vaccines for preventing influenza in healthy children. Cochrane Database Syst Rev. 2008;(2):CD004879.

White N, Webster R, Govorkovs E et al. What is the optimal therapy for patients with H5N1 infection? PLoS Med. 2009;6:e1000091.

\section{TRADUTORES:}

Luís Filipe Gomes, MD, EMGF - 21/08/2009

Maria Isabel Santos, PhD - 07/09/2009

\section{ABSTRACT}

\section{DEALING WITH THE PANDEMIC INFLUENZA CALLS FOR PATIENCE AND TRANQUILLITY - VERSION N 9}

Influenza A (H1N1) is very contagious and of scarce severity. It is less dangerous than the usual seasonal flu.

When dealing with influenza $A(\mathrm{H} 1 \mathrm{~N} 1)$ it is fitting to keep up a prudent and calm conduct, much like the one we adapt with the seasonal flu.

The doctor must be consulted only in case of grave illness (coughing up blood, great respiratory deterioration).

The antiviral drugs Tamiflu and Relenza do not prevent influenza A (H1N1), and have significant side effects. They must be reserved for serious cases.

The vaccine against influenza $A(\mathrm{H} 1 \mathrm{~N} 1)$ is on an experimental stage, and presently there is no information about its safety and efficiency.

The previous pandemics did not cause great mortality once the antibiotics that treat the flu-related pneumonias became available. Moreover, these pandemics did not have a second outburst of greater aggressiveness.

In addition to influenza $A(H 1 N 1)$, the health care services have to deal with the thousands of usual acute and chronic patients; the activity of doctors, nurses and remaining staff must not become saturated with patients that have mild influenza $A$ (H1N1). 